\title{
Natural Hazard Risk Management: a Multidisciplinary Approach to Define a Decision Support System for Shallow Rainfall-Induced Landslides
}

\author{
N. Netti ${ }^{1, *}$, E. Damiano ${ }^{2}$, R. Greco ${ }^{2}$, L. Olivares ${ }^{2}$, V. Savastano ${ }^{3}$ and P. Mercogliano ${ }^{4}$ \\ ${ }^{I}$ Department of Economics - University of Naples "Federico II", Naples, Italy \\ ${ }^{2}$ Department of Civil Engineering - Second University of Naples, Aversa (CE), Italy \\ ${ }^{3}$ STIIA (Sistemi Territoriali Integrati per l'Ingegneria Ambientale) - Ercolano (NA), Italy \\ ${ }^{4}$ CMCC-Mediterranean Centre for Climate Change, Capua, Italy
}

\begin{abstract}
The paper presents a Multidisciplinary Decision Support System (MDSS) to analyse rainfall-induced shallow flowslides on steep slopes covered by pyroclastic deposits. This system proposes an approach to provide technical information to the agencies responsible for civil protection and land management about the link between forecasted rainfall and the effects in terms of infiltration, slope stability, vulnerability and mitigation policy. This approach was developed at the Euro-Mediterranean Centre for Climate Change (CMCC) (meteorological aspects), at the Department of Civil Engineering of the Second University of Naples (hydrological and geotechnical aspects) and at the Department of Economics of the University of Naples "Federico II" (socio-economic aspects). It has been designed as a multidisciplinary approach which simultaneously addresses the issues from different points of view, providing a comparison and integration of the different skills. The potentiality of this approach is presented for the case of the flowslide of Cervinara (Southern Italy).
\end{abstract}

Keywords: Risk management, unsaturated soil, suction, shear strength, liquefaction, economic growth, poverty traps.

\section{INTRODUCTION}

The scope of this research is to develop models useful for the analysis of meteorological, hydrological, geotechnical and economic aspects with regard to shallow flowslides in pyroclastic deposits caused by intense precipitations. In recent years, the interest in the development of such models has grown, owing to the increased frequency of heavy rainfall events associated with a constant increase of the use of the land. Such aspects are extremely important, especially in the case of landslides with evolution in flowslides, because of the very long distance that huge saturated soil masses can cover and their enormous disruptive effects. The analyses of these aspects require the institutions responsible for land management and civil protection to have available useful instruments, able to forecast and eventually to prevent the catastrophic effects of flowslides and to correctly allocate resources. The best approach to the problem is a multidisciplinary one, simultaneously addressing the issues from different points of view.

After a brief discussion on the possibility of forecasting rainfall-induced landslides with evolution in flowslide (section 2), the components of a Multidisciplinary Decision Support System (MDSS in the following) are presented (Fig. 1).

In section 3, economic aspects (socio economic perspective) are treated, highlighting, on one hand, the limits of

*Address correspondence to this author at the Department of Economics University of Naples "Federico II", Naples, Italy; Tel. +39 081 675023;

Fax:+39081675014; E-mail: netti@unina.it; ex-post protective measurements against natural hazards and, on the other, the difficulties that arise in the case of ex-ante Environmental Risk Assessment.

In section 4, meteorological aspects are treated with a brief description of the computational weather model (indicated in the following as COSMO LM) which can satisfactorily anticipate the evolution of the weather and its changes due to interactions with orography and in particular the forecasted rainfall in the case of very intense events.

In section 5, hydrological and geotechnical aspects are treated in a module of infiltration and stability analyses for unsaturated soils (indicated in the following as I-MOD3D) able to "concatenate" the results of the meteorological models with the analysis of the effects in terms of infiltration and slope stability. The output of COSMO-LM is used to define the top boundary conditions for I-MOD3D.

In section 6, the results of the application of the MDSS to three selected test cases occurred during 2007 are reported.

\section{EVOLUTION OF LANDSLIDE IN PYROCLASTIC DEPOSITS: FLOWSLIDE GENERATION}

The analysis of steep slopes $\left(\alpha>\phi^{\prime}\right)$ in unsaturated cohesionless pyroclastic deposits subjected to long-lasting infiltration processes using a hydrological/geotechnical model is of fundamental importance. In the recent decades catastrophic flowslides have more and more frequently threatened and partially destroyed small towns in the foothills of Campania's Apennines in Southern Italy. The most severe events occurred in Sarno (1998), Quindici (1998), Bracigliano (1998) and Cervinara (1999). These kinds of 


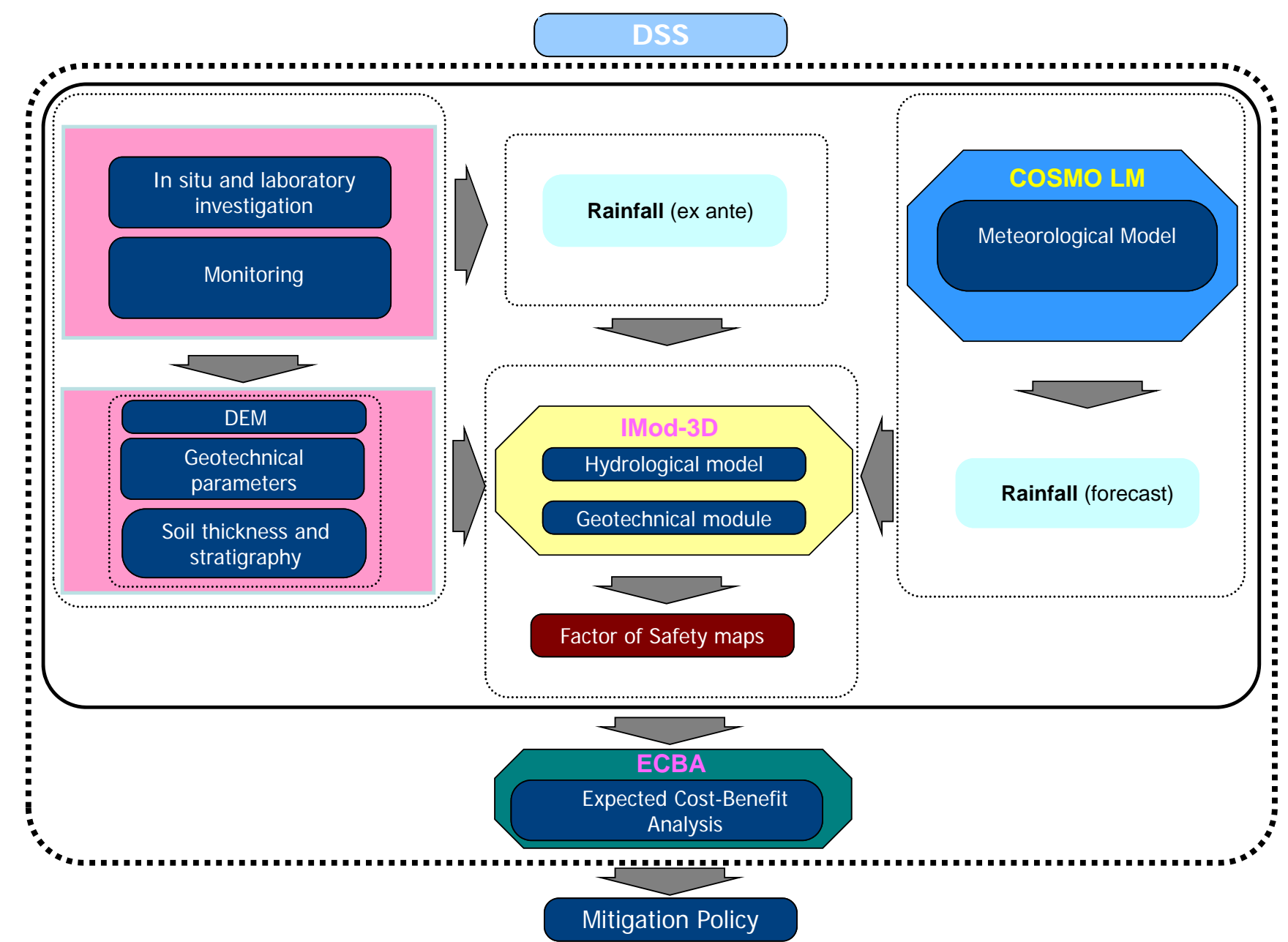

Fig. (1). Flow chart of the Decision Support System (DSS).

landslides involved, mainly, cohesionless pyroclastic deposits laying upon fractured limestone, initially unsaturated that, after the failure of the slope, evolved into a fully saturated flowing mass with high degree of fluidity, able to travel several kilometres at very high speed and with a huge disruptive impact.

In literature [1-10], the flowslide generation in saturated granular deposits is generally linked to the susceptibility to liquefaction and, hence, under shear load, to the establishment of an unstable undrained response, characterized by progressive decrease of shear strength due to the development of positive excess pore pressure (static liquefaction).

However, it should be considered that, in the case of unsatured pyroclastic liquefiable deposits, landslides evolving into flowslides are somewhat rare. Frequently, after intense but not long lasting rainfalls, landslides occurring along very steep slopes stop at the toe of the slope without severe consequences. According to $[6,10-12]$, this is due to the state properties at failure that strongly influence the mobility of the material and the establishment of drained or undrained post-failure mechanism.

In an initially unsatured pyroclastic deposit, two conditions are necessary for an unstable post-failure response with evolution into flowslide to happen: (1) the soil must be susceptible to liquefaction and (2) the instability must occur near saturation $[6,12]$.
Therefore, quantitative prediction of the evolution of hydrological and geotechnical variables such as water content, degree of saturation and suction, corresponding to forecasted rainfall is of paramount importance, for the authorities in charge of land management, to detect cases in which rainfallinduced slope failure may evolve into flowslides. In fact, such information allows excluding the cases of landslides that will not evolve into catastrophic flowslides, with a reduction of the false alarms [13, 19].

\section{PROTECTIVE MEASURES AGAINST NATURAL HAZARDS: SOCIO-ECONOMIC PERSPECTIVE}

The economic growth may be seriously compromised by (ex-post) direct and indirect effects of catastrophic events even in the case of developed countries. That is why we believe that economies do have to cope (ex-ante) with natural hazards.

Governments, mainly concerned about subjective perceptions of voters and taxpayers, do not pay sufficient attention to scientific advice. However, public perceptions about natural hazards are too often inconsistent with any objective information; people exhibit too little concern about some hazards and too much concern about others. If, as a consequence, governments devote scarce resources to coping (ex-ante) with natural hazards, limits to economic growth and 'poverty traps' may stem from (ex-post) direct and indirect effects of catastrophic events that deeply compromise growth. 
As far as ex-ante Environmental Risk Assessment and Management is concerned, it is generally performed in the presence of extremely high degrees of uncertainty. Much of the uncertainty is due to the poor understanding of all the components of the chain from meteorological to hydrological and geotechnical aspects.

This high level of uncertainty may produce very high economic costs whose magnitudes compromise the ability of society to manage natural risks and mobilize adequate resources. This has potentially serious macroeconomic consequences. Under such uncertain conditions, decision-makers are induced to develop adaptation strategies that do not look for optimality but for robustness in face of many possible alternative outcomes of each potential natural hazard [14]. Natural Hazard Risk Managers, therefore, need to implement strategies able to cope with many possible scenarios often dealing more with 'ambiguity' than with 'risk' .

We propose our MDSS to better deal with all the uncertainty in ex-ante Environmental Risk Assessment and Management. In fact, this MDSS is able to supplement other systems already available at Basin Authorities and Civil Protection agencies that are currently used to alert population only through pluviometric empirical thresholds based on observed rainfall time series. In fact, the proposed MDSS makes an objective evaluation of the effects of rainfall events through the analysis of the infiltration processes and of the corresponding evolution of stress variables. Therefore, it allows a correct evaluation of the triggering of landslides, thus reducing the number of false and/or missed alarms owing to the current use of only empirical thresholds and/or of other simplified qualitative or semi-quantitative approaches. Indeed, the costs deriving from false and/or missed alarms may sometimes be comparable to those of the event itself.

Furthermore, additional uncertainty, in terms of potential welfare losses, is caused by the difficulty of evaluating the adaptive capacity of various economic sectors [27]. This is mostly due to the lack of models integrating economic aspects with meteorological, hydrological and geotechnical aspects.

This point is usually neglected, but it is likely to be one of the most important sources of uncertainty in the cause and effect chain linking the results of the weather forecast models with the analysis of the effects of extreme rainfall at the ground in terms of rainfall infiltration and slope stability.

The problem posed by the integration of economic aspects in the risk analysis is exacerbated by the difficulty of predicting the propagation of flowslides and, consequently, of quantifying the exposed goods [26]. Modelling the propagation of flowslides relies upon the description of the complex rheological behaviour of the flowing material. So far, in the geotechnical and hydrological literature few attempts were done only by means of 'back analyses' of past events, but a useful real time cost-benefit analysis should be based on predictions at high confidence levels. A flowslide propagation module will be added to our MDSS in future developments of the research.

\footnotetext{
${ }^{1}$ In economic literature about decision under uncertainty, when clear probabilities are involved it can be used the term 'risk' but if, otherwise, vague probabilities are involved; the phenomenon is called 'ambiguity'[15].
}

\section{METEOROLOGICAL MODEL: COSMO-LM MODEL}

The code employed for weather simulations is the COSMO-LM model, developed within the "Consortium for Small-Scale Modeling - Local Model" [16]. The consortium is formed by the Italian Air Force, regional agencies for environmental protection (ARPA Emilia Romagna and Piemonte) and CIRA (Centro Italiano Ricerche Aerospaziali), in addition to the meteorological services of six different countries (Germany, Greece, Italy, Poland, Romania and Switzerland). This model is operationally used for weather forecasting in many European countries; currently, in Italy it is adopted by the forecasting systems of the National Civil Protection Functional Centres. The forecast is based on initial and boundary conditions from atmospheric global model (Integrated Forecast System) described in [17]. It is a global spectral model for weather forecasting with a horizontal resolution of about $20 \mathrm{~km}$ and a temporal resolution of 10 days. To achieve higher resolution forecasts, two limited area models (COSMO-LM) are utilized [18]: the first with horizontal resolution of $7 \mathrm{~km}$ and temporal forecast range of up to 72 hours, the second with horizontal resolution of $2.8 \mathrm{~km}$ and temporal forecast range of up to 24 hours. COSMO-LM is a non-hydrostatic limited area atmospheric prediction model; it is based on primitive thermo-hydrodynamic equations describing compressible flow in a moist atmosphere. The model equations are formulated in rotated geographical coordinates and a generalized terrain. A variety of physical processes are taken into account by the parameterization scheme (grid scale cloud and precipitation, moist convection, radiation, heat and water exchange between soil and atmosphere, surface layer and subgrid-scale turbulence). The prognostic variables of the model are horizontal and vertical Cartesian wind components, pressure perturbation, temperature, specific humidity, cloud water content and optionally cloud ice content, turbulent kinetic energy, specific water content of rain and snow.

Finally, an interpolation plug-in module for ArcGIS automatically elaborates, given a COSMO LM precipitation forecast, finer resolution precipitation data. The calculated ArcGIS raster data can be directly read by the hydrological and geotechnical model I-MOD3D described in the following section.

\section{HYDROLOGICAL/GEOTECHNICAL MODEL I- MOD3D}

The analysis of the infiltration process and of its consequences on the equilibrium of a slope is carried out with the I-MOD3D model $[12,19,26]$. It consists of a finite volumes module for 3D water flux modeling through homogeneous rigid unsaturated soil, neglecting the flux of the gaseous phase and considering isothermal conditions, coupled with a slope equilibrium model based on the simplifying assumption of infinite slope geometry.

The infiltration model solves the 3D Darcy-Buckingham motion equation coupled with the water mass balance equation:

$$
\bar{v}(x, y, z, t)=-K[\theta(x, y, z, t)] \nabla\{z+\psi[\theta(x, y, z, t)]\}
$$

$\frac{\partial \theta}{\partial t}=-\nabla \cdot \bar{v}(x, y, z, t)$ 
In equations (1) and (2) $\bar{v}$ represents the unit water flux vector; $\psi$ is the capillary pressure head; $\theta$ is the volumetric water content of soil; $\mathrm{K}$ is the hydraulic conductivity of unsaturated soil.

The hydraulic behavior of the soil is described by introducing in equations (1) and (2) appropriate expressions for the water retention curve $\psi(\theta)$ and for the hydraulic conductivity function $K(\theta)$. In the proposed model, they are described with the expressions proposed by Van Genuchten [22] and Brooks and Corey [23], respectively:

$\frac{\theta-\theta_{\text {res }}}{\theta_{\text {sat }}-\theta_{\text {res }}}=\frac{1}{\left[1+(\alpha|\psi|)^{n}\right]^{m}}$

$K=K_{\text {sat }}\left(\frac{\theta-\theta_{\text {res }}}{\theta_{\text {sat }}-\theta_{\text {res }}}\right)^{\delta}$

Therefore, for the hydraulic characterization of the unsaturated soil, the adopted expressions require the assignment of appropriate values to seven parameters: $\theta_{\text {sat }}$, the volumetric water content of the soil at saturation; $\theta_{\text {res }}$, the residual water content of the soil; $\mathrm{K}_{\text {sat }}$, the hydraulic conductivity of the soil at saturation; $\alpha, n, m$, and $\delta$, shape parameters related with the pore size distribution of the soil.

Equations (1) and (2) must be completed with initial and boundary conditions. The initial condition is an assigned distribution of capillary pressure head within the soil domain to be modeled. The boundary conditions have to be assigned at soil surface and at the soil-bedrock interface below the soil layer. Usually, infiltration/evaporation fluxes are assigned at the top soil surface. The bottom boundary condition depends on the characteristics of the soil-bedrock interface and can be either an assigned flux (e.g., null flux in case of impervious bedrock) or an assigned value of capillary pressure head (e.g., null capillary pressure head if an aquifer is supposed to exist at a given depth).

In the module of slope equilibrium, at each point where the capillary pressure head has been provided by the hydrological module, the safety factor (i.e., the ratio between limit balancing forces and unbalancing forces acting along planes parallel to the slope surface) is calculated under the hypothesis of infinite slope geometry:

$S F=\frac{\tau \lim }{\tau \vartheta}=\frac{c^{\prime}+f\left(u_{a}-u_{w}\right)+\left(\sigma \vartheta-u_{w}\right) \tan \phi^{\prime}}{\gamma d \sin \vartheta \cos \vartheta}$

In equation (5), in which the safety factor is written in terms of shear stresses (forces acting along unit surfaces), $\theta$ is the slope inclination angle; $\tau \vartheta$ and $\sigma \vartheta$ are the shear and normal stresses of soil along planes parallel to the slope surface; $u_{\alpha}$ is pore air pressure (assumed in the model equal to atmospheric pressure); $u_{W}$ is the pore water pressure (i.e., capillary pressure in unsaturated conditions); $c^{\prime}$ and $\phi^{\prime}$ are soil effective cohesion and friction angle, respectively; $\gamma$ is the bulk unit weight of unsaturated soil; $d$ is the depth below the slope surface. The shear strength $\tau_{\text {lim }}$ is evaluated according to the extension of the Mohr-Coulomb criterion to unsaturated soils [24]; the term $f\left(\mathrm{u}_{\mathrm{a}}-\mathrm{u}_{\mathrm{w}}\right)$, accounts for the contribution of suction to shear strength of soil.

The model, which allows automatically generating the finite volumes mesh from a Digital Terrain Model of the slope, has been developed as a Visual Basic Application for
ARC-GIS 9.2, through which it is possible to visualize thematic contour maps of safety factors as well as of all the computed hydrologic variables ( $\psi, \theta$, and so on).

\section{TEST CASES}

The Cervinara area in Campania (Southern Italy) has been selected to evaluate the proposed simulation chain (Fig. 2) as an example of the geomorphological context characterized by volcanic ashes resting upon fractured limestone involved in a catastrophic flowslide (1999). Data from in situ investigations and monitoring of suction and rainfall are available, as well as data about mechanical and hydraulic properties of the involved soils (for details about experimental activities and geotechnical modelling see [10, 12, 13, 19$21,26,28-30])$. The landslide area, investigated with boreholes and shallow pits, has fairly regular steep slopes (average slope angle $40^{\circ}$ ) consisting of an unsaturated air-fall pyroclastic deposit in primary deposition overlying fractured limestone. In particular, the deposit in the detach area has average thickness of $2.4 \mathrm{~m}$ and slope angle ranging between $35^{\circ}$ (toe) and $55^{\circ}$ (crest).

Since 2002, rainfall data are available from a monitoring system managed by the Second University of Naples (SUN) operating at Cervinara on the slope where the flowslide of 1999 occurred. The monitoring system includes a rain gauge and several tensiometers for soil suction measurements.

The data on slope morphology (aerophotogrammetry at the scale of 1:5000) and soil properties were combined to define the hydrological/geotechnical model of the area in Fig. (3). The slope was discretized in the IMOD-3D module with a $3 \mathrm{D}$ mesh generated from the DEM with a cell size of $\mathrm{dx}=\mathrm{dy}=5 \mathrm{~m}$ and $\mathrm{a}$ constant $\mathrm{dz}=0.12 \mathrm{~m}$.

Three rainfall events occurred in 2007 were selected to test the performance of the simulation chain comparing observed and predicted rainfall and suction in the subsoil. During these events no landslide occurred.

\subsection{Hydrological/Geotechnical Model}

The infiltration process was numerically simulated assuming the hypothesis of homogeneous deposit and applying either the average daily rainfall intensity observed during rainy days (pluviometric measurements), or the evaporation flux during dry days (estimated from Cervinara suction measurements $[13,20]$ ), as top soil surface boundary condition. For the lateral and bottom boundary conditions, free flow was assumed.

The calibration of the model was carried out through a parametric analysis, investigating the range of variation of soil parameters obtained from laboratory tests (summarized in Fig. 3) assuming as initial conditions a constant value of suction equal to the mean value $(10 \mathrm{kPa})$ observed at the Cervinara monitoring station at the beginning of the simulation (January 2006).

Figs. (4 and 5) show the upper boundary condition in terms of applied daily rainfall, cumulative rainfall height, IN-OUT water daily flux, and cumulative IN-OUT water flux height $[13,20]$.

The best fitting between modelled and measured soil suction was obtained with the following soil properties: 


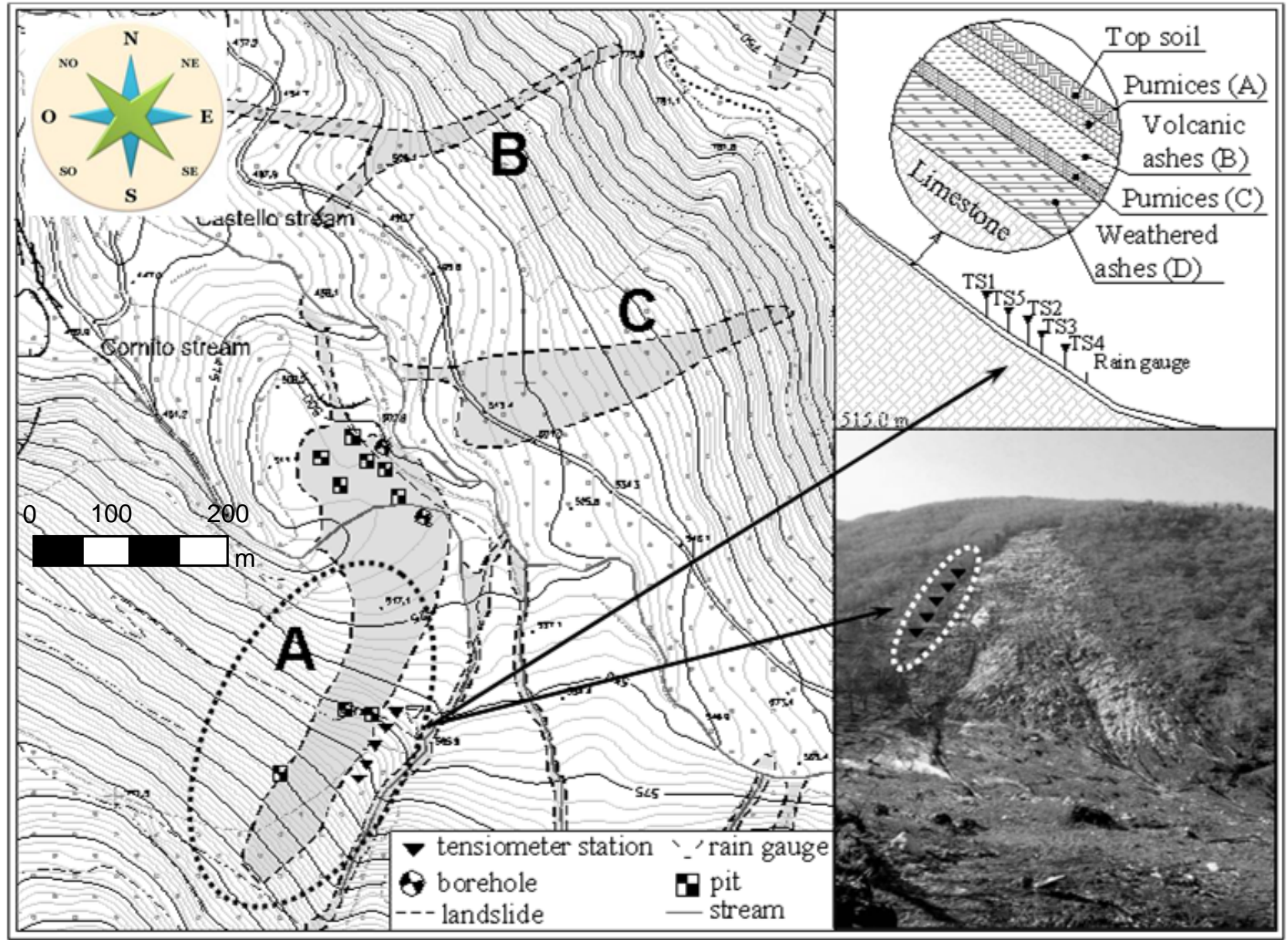

Fig. (2). Flow chart of the Decision Support System (DSS).

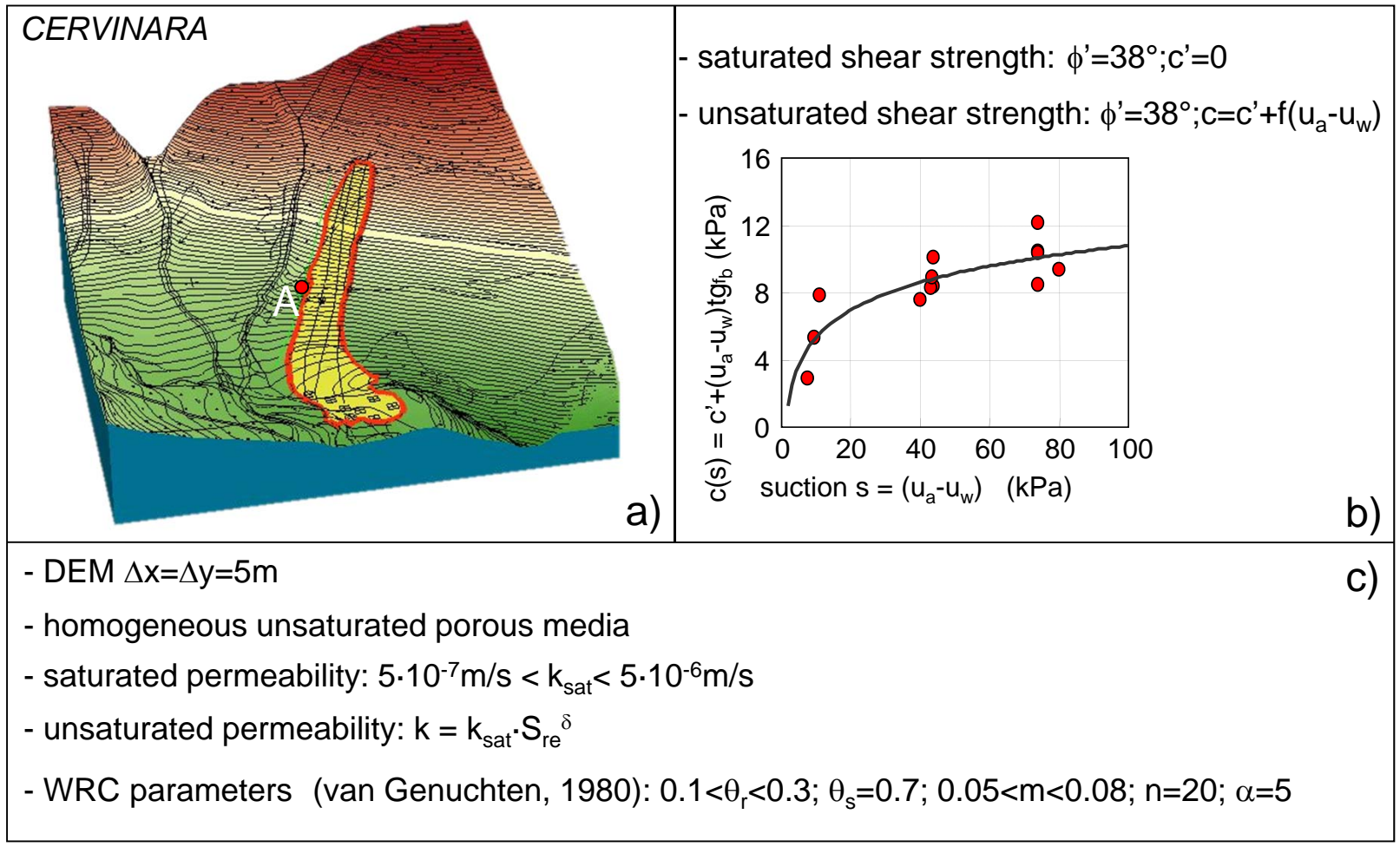

Fig. (3). Hydrological/Geotechnical Model. 

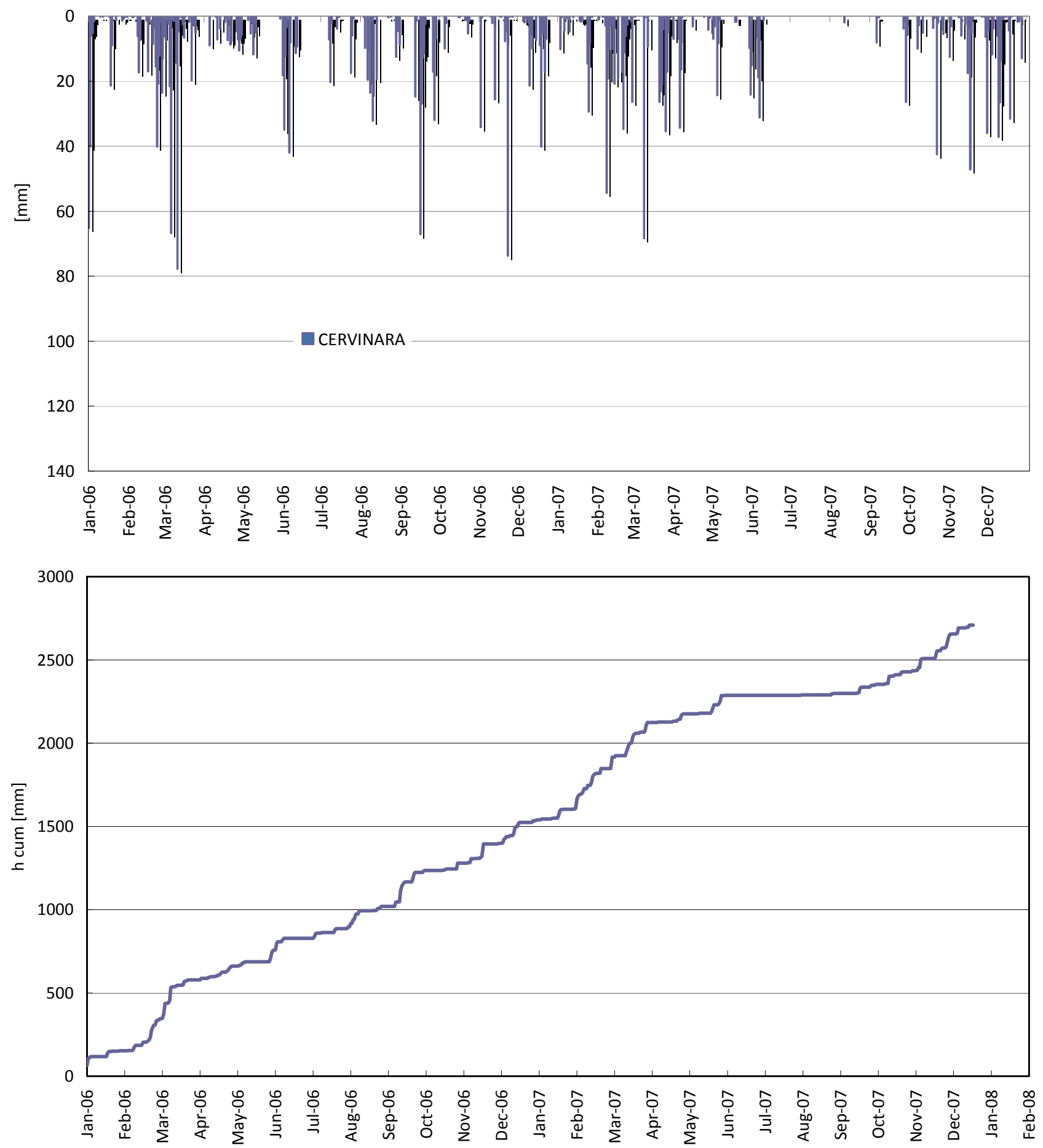

Fig. (4). Boundary conditions applied in terms of daily and cumulative rainfall height (Cervinara 2006-2007) 

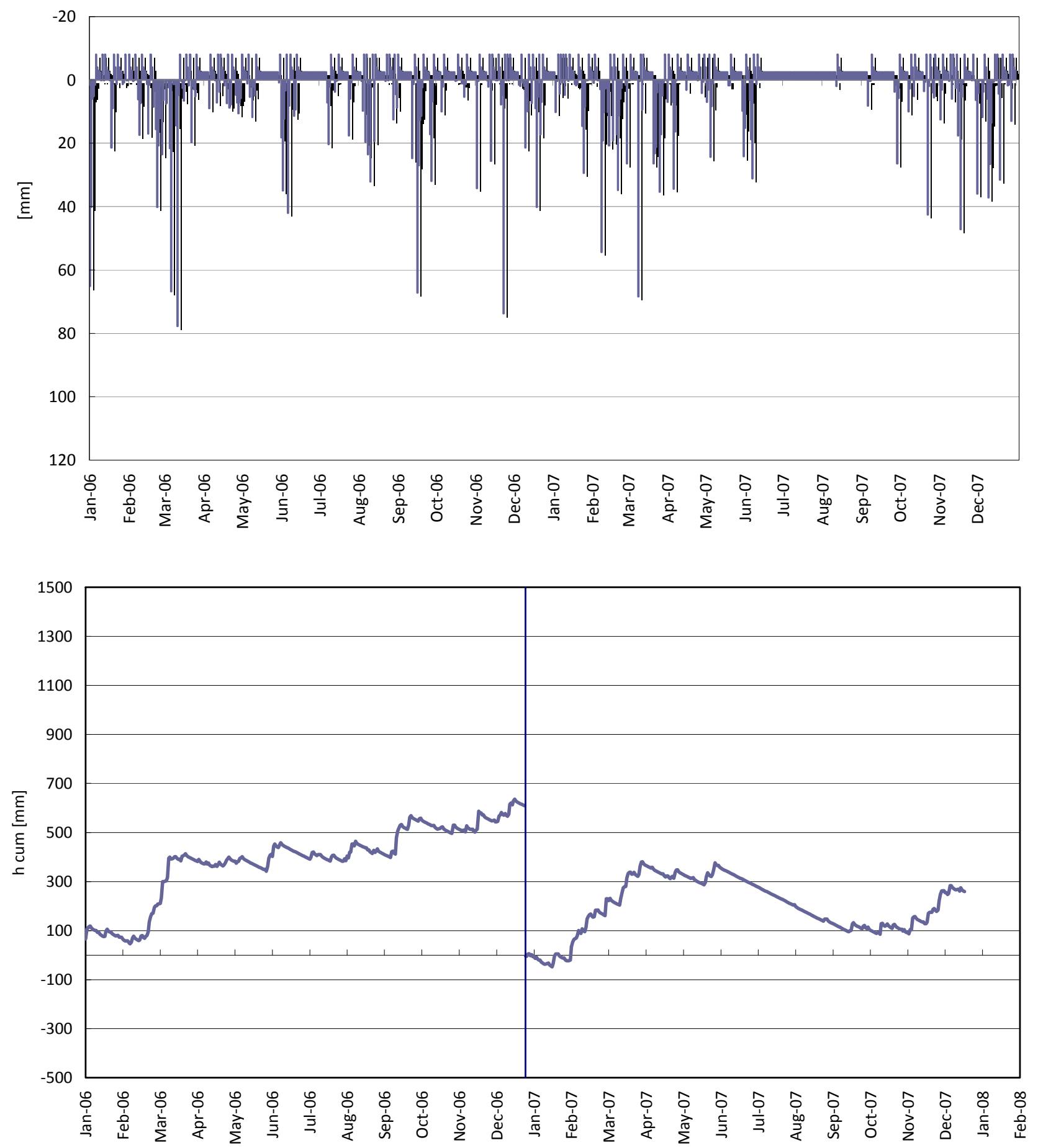

Fig. (5). Boundary conditions applied in terms of IN-OUT water flux and cumulative infiltration height (Cervinara 2006 and 2007).

- for the water retention curves the van Genuchten expression [22] with $\theta_{\mathrm{s}}=0.7, \theta_{\mathrm{r}}=0.1, \mathrm{~m}=0.08, \mathrm{n}=20, \alpha=5$;

- for the unsaturated hydraulic conductivity functions the Brooks and Corey expression [23] with the mean saturated conductivity estimated in the laboratory tests $\left(\mathrm{k}_{\mathrm{sat}}=1 \mathrm{E}-6 \mathrm{~m} / \mathrm{s}\right)$, a nil value of the residual water content, and $\delta=3$.
In Fig. (6) the simulated suction trends between the depths of $0.6 \mathrm{~m}$ and $1.5 \mathrm{~m}$ are shown for point A of Fig. (3), located on the right side of the landslide, where the slope inclination angle is $40^{\circ}$ and the thickness of the pyroclastic cover is $2.4 \mathrm{~m}$. In wet periods, good agreement between measured and simulated suctions was obtained, while in dry periods the predicted trend resulted only qualitatively in 


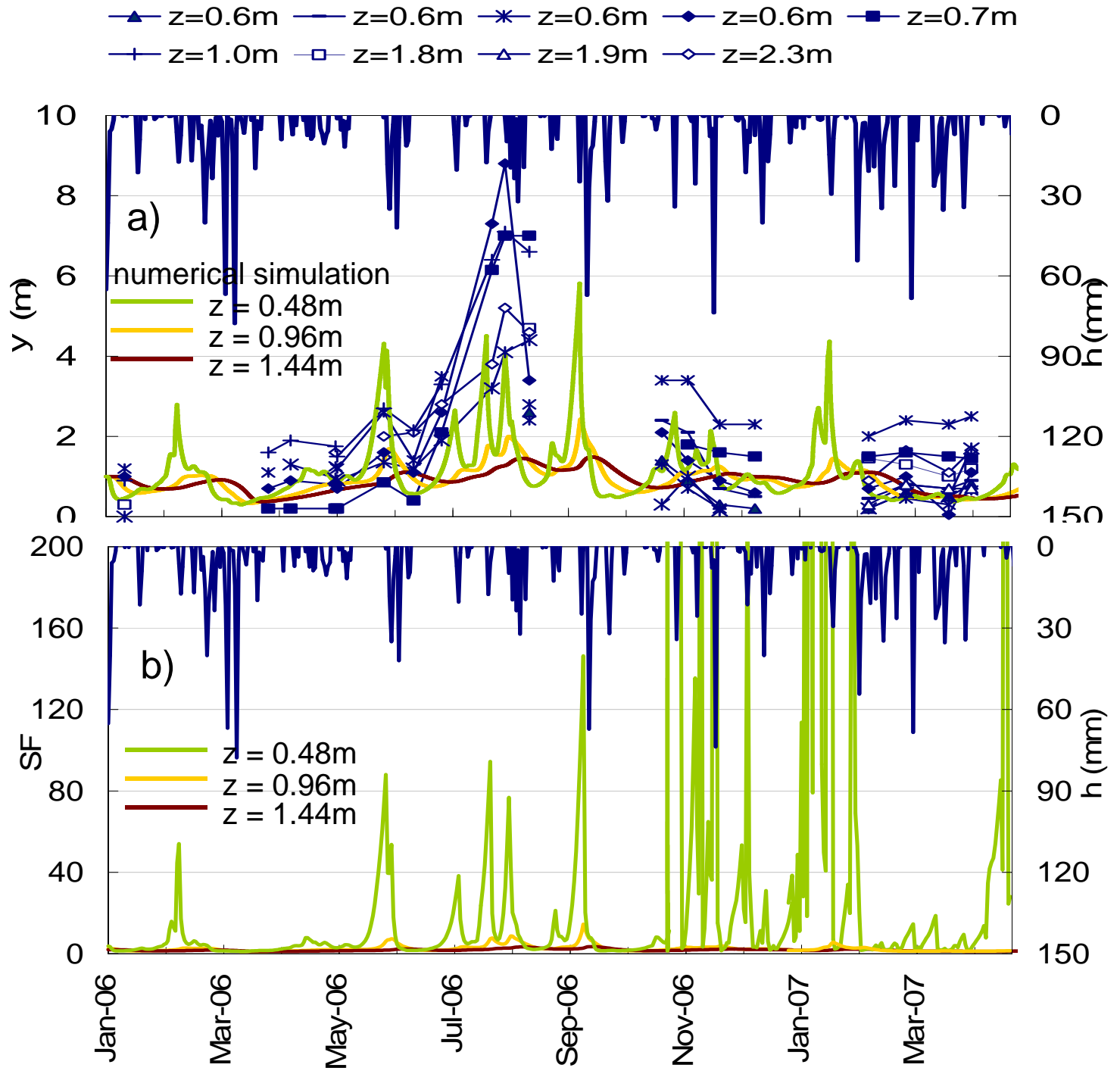

Fig. (6). Cervinara case: numerical simulation results; a) comparison between the capillary pressure head measurements, rainfall and simulation results; b) safety factor trend.

agreement with measurements and characterised by lower values. This disagreement in dry periods between simulated and measured suction trends can be probably ascribed to two reasons:

- the simplified assumptions on evaporation flux applied in the model at soil-atmosphere interface, that do not take properly into account the effects of transpiration in the shallowest layer due to the presence of vegetation (brushwood and chestnut wood);

- the inability of the selected hydraulic conductivity function to correctly simulate the unsaturated soil response.

Given that, the agreement between measured and simulated suction in wet period seems to satisfy the MDSS requirements as it allows a reasonably accurate estimate of the evolution of slope equilibrium conditions. In fact, again for point A of Fig. (3), Fig. (6) shows the computed evolution of the safety factor at various depths. The minimum values, obtained in wet periods, resulted always higher than 1 , as expected, since no landslides occurred in the considered period.
The histogram of the frequency of suction values observed between 2002 and 2007 is reported in Fig. (7), showing that the most frequent suction values fall in the range 4$16 \mathrm{kPa}$ in a set of 213 data. Suction values higher than 70 $\mathrm{kPa}$ were observed only a few times. As in Damiano and Olivares [13], in the same figure also the water retention curve used for numerical simulations is plotted, along which three ranges of suction may be distinguished [25]:

- red zone I, between 0 and the value of suction corresponding to the air-entry value (point A in Fig. 7);

- yellow zone II, between points A and B corresponding to the maximum curvature of the SWRC;

- green zone III for higher values of suction.

This distinction in red, yellow and green zones, can be used to evaluate the saturation conditions of the soil at the onset of instability; as previously stated in section 2 , such conditions affect the post-failure evolution of a landslide.

Indeed, for different slope angles and depths, every point of the water retention curve can be representative of a poten- 


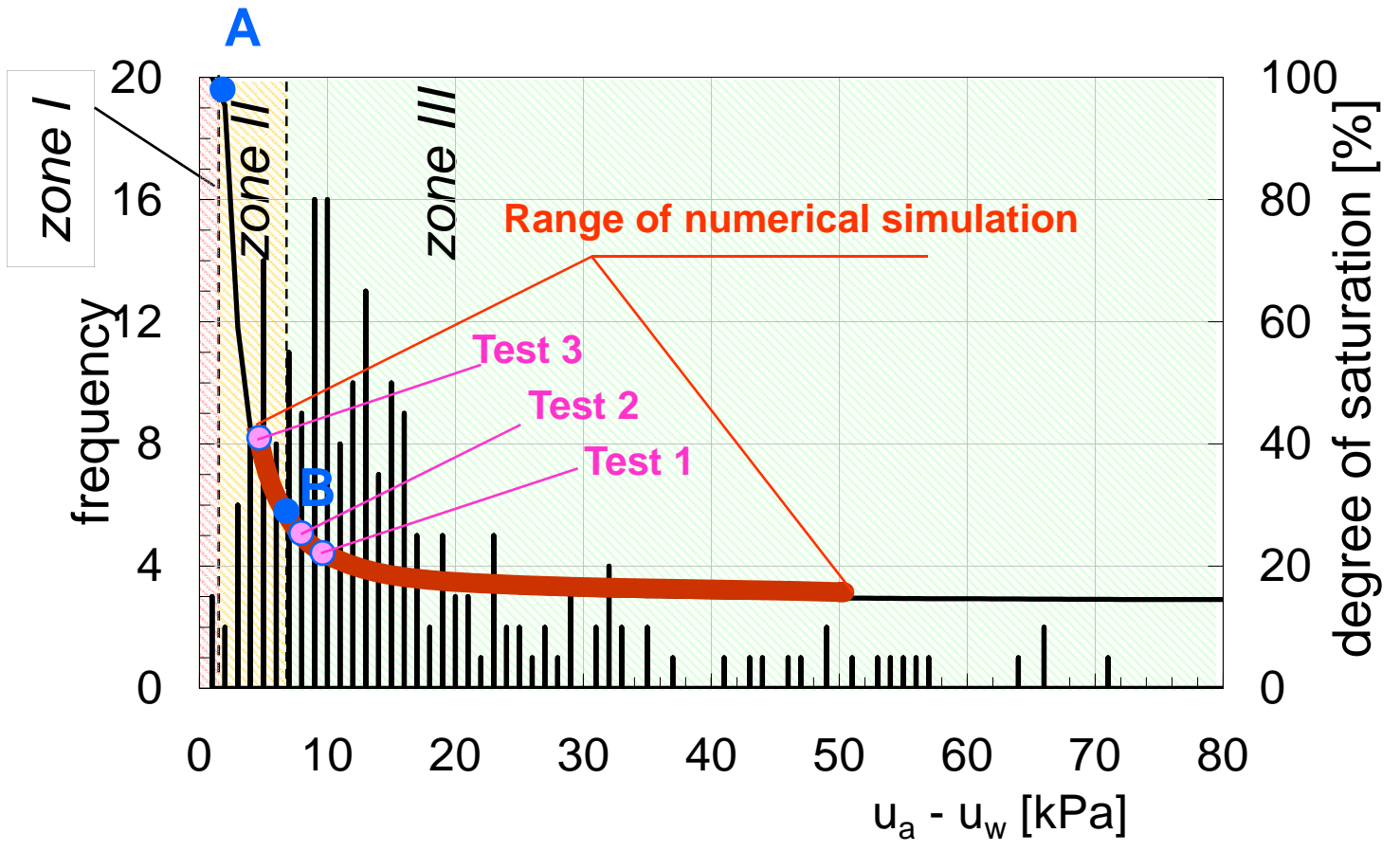

Fig. (7). Histogram of the frequency of suction from monitoring and water retention curve used for numerical saturation; distrintion in red yellow and green zone to evaluate the saturation condition at the onset of instability.

tial instability condition (e.g., point A of Fig. (7) is representative of failure conditions at every depth for a slope angle of $38^{\circ}$, while point $\mathrm{B}$ corresponds to failure condition at $2.4 \mathrm{~m}$ of depth for a slope angle of $47^{\circ}$ ). Therefore, it can be stated that:

- if the state of the soil at failure is characterized by a point located in the green zone (zone III in Fig. 7), the soil is still far from complete saturation and unstable post-failure evolution into a flowslide is unlikely.

- if the soil state corresponds to a point within the red zone, failure can involve soil near saturation and the post-failure type of movement is likely to be a flowslide.

Obviously, when the point representative of soil state falls in the yellow zone, attention has to be paid since a flowslide may be triggered if the soil approaches a saturated condition after rainfall infiltration.

The histogram of Fig. (7) shows that the most usual saturation conditions observed in situ fall in the green zone, while the degree of saturation falls in the red zone with a very low frequency.

A similar conclusion can be drawn from the range of variation obtained at every depth in the numerical simulations of years 2006 and 2007 for point A of Fig. (3), plotted in the same figure (red curve). Although either the measured data or the simulated values are representative of equilibrium conditions (no landslide was observed), it can be concluded that, during the considered period, the preconditions for the triggering of a flowslide never occurred.

\subsection{Application of the Simulation Chain}

The proposed MDSS was applied to three test cases. The tests consisted of predictions of the effects on slope equilibrium of the rainfall forecasted in 48/120 hours.
The selected dates were:

1. - 6 February $2007(\Delta \mathrm{t}=120 \mathrm{~h})$ (Fig. 8).

2. - 6 March $2007(\Delta \mathrm{t}=48 \mathrm{~h})$ (Fig. 9);

3. - 3 April $2007(\Delta \mathrm{t}=48 \mathrm{~h})$ (Fig. 10);

The initial conditions in terms of suction and volumetric water content for the numerical analyses were derived, for the three dates, from the calibration phase presented in the previous section (Fig. 6).

The first case is representative of a rainfall of low cumulative height $(12 \mathrm{~mm})$ distributed over a long period (120 hours); in the other two cases, the simulation period was 48 hours and the cumulative rainfall was about $20-30 \mathrm{~mm}$ but, in the second case, the rain was distributed over 34 hours while in the third case along a much shorter period (15 hours). Although the occurrence of the rainfall event was qualitatively forecasted, the weather model is far from providing reliable quantitative values of rainfall height, since it predicted about half of the observed rainfall height.

The Cervinara slope response predicted by the IMOD-3D module is reported in Figs. (11 to 16). Figs. (11, 13 and 15) show the results of the numerical simulation of the infiltration process in terms of safety factor SF for point A of Fig. (3). As expected, a strong reduction in the safety factor occurs only in the shallowest portion of the deposit (from the ground surface up to the depth of about $40-60 \mathrm{~cm}$ ). The effects of rainfall infiltration are instead negligible at greater depths.

Similar information can be obtained from Figs. (12, 14 and 16) in which, again for point A along the slope (Fig. 3), the same simulations are analyzed in terms of capillary pressure height $(\psi)$, volumetric water content $\left(\theta_{\mathrm{w}}\right)$ and safety factor $(F S)$ profiles. 

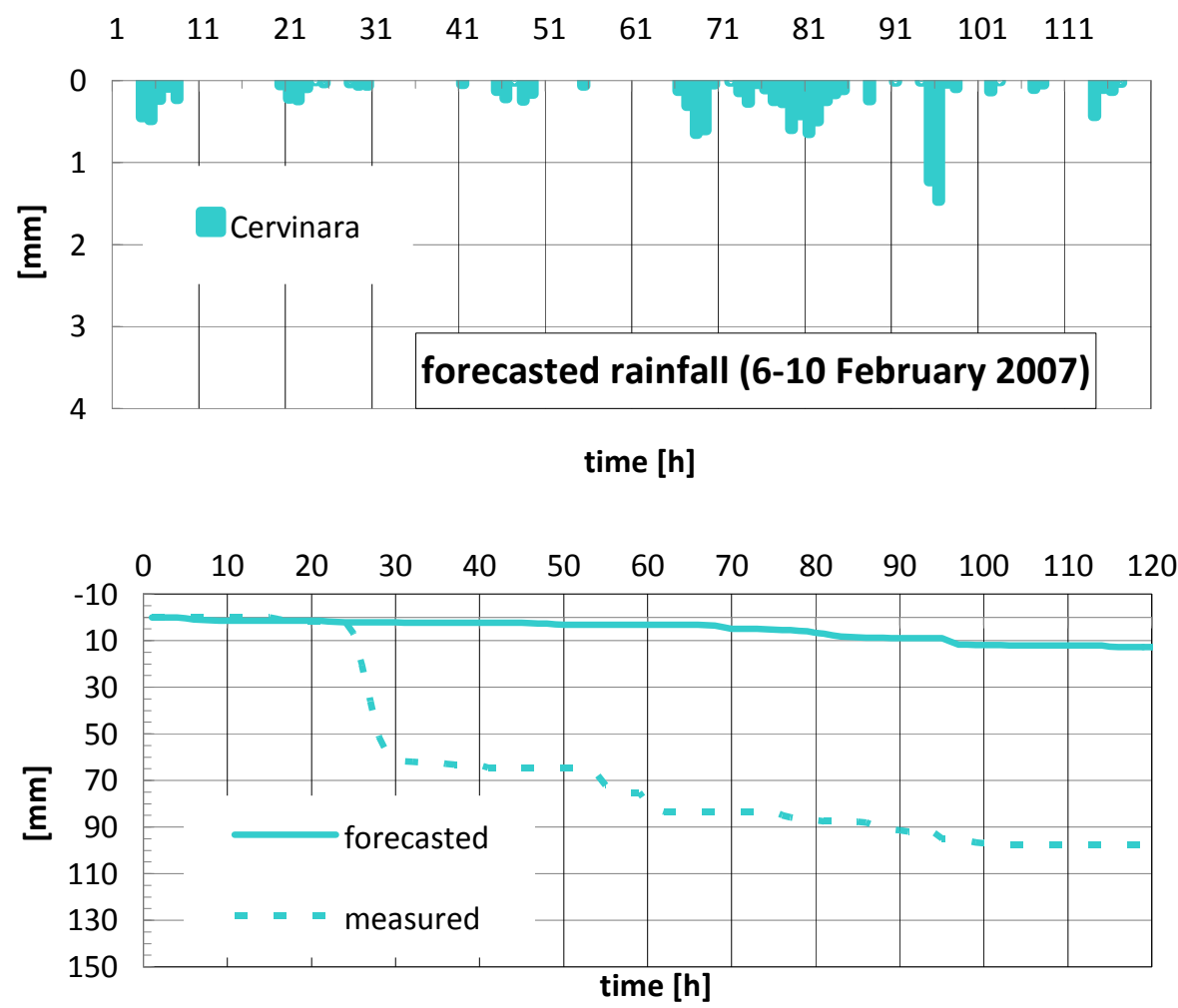

Fig. (8). First test case: hourly rainfall height and cumulative rainfall height during 6-10 February 2007, evaluated at point A of Fig. (3) in the site of Cervinara.
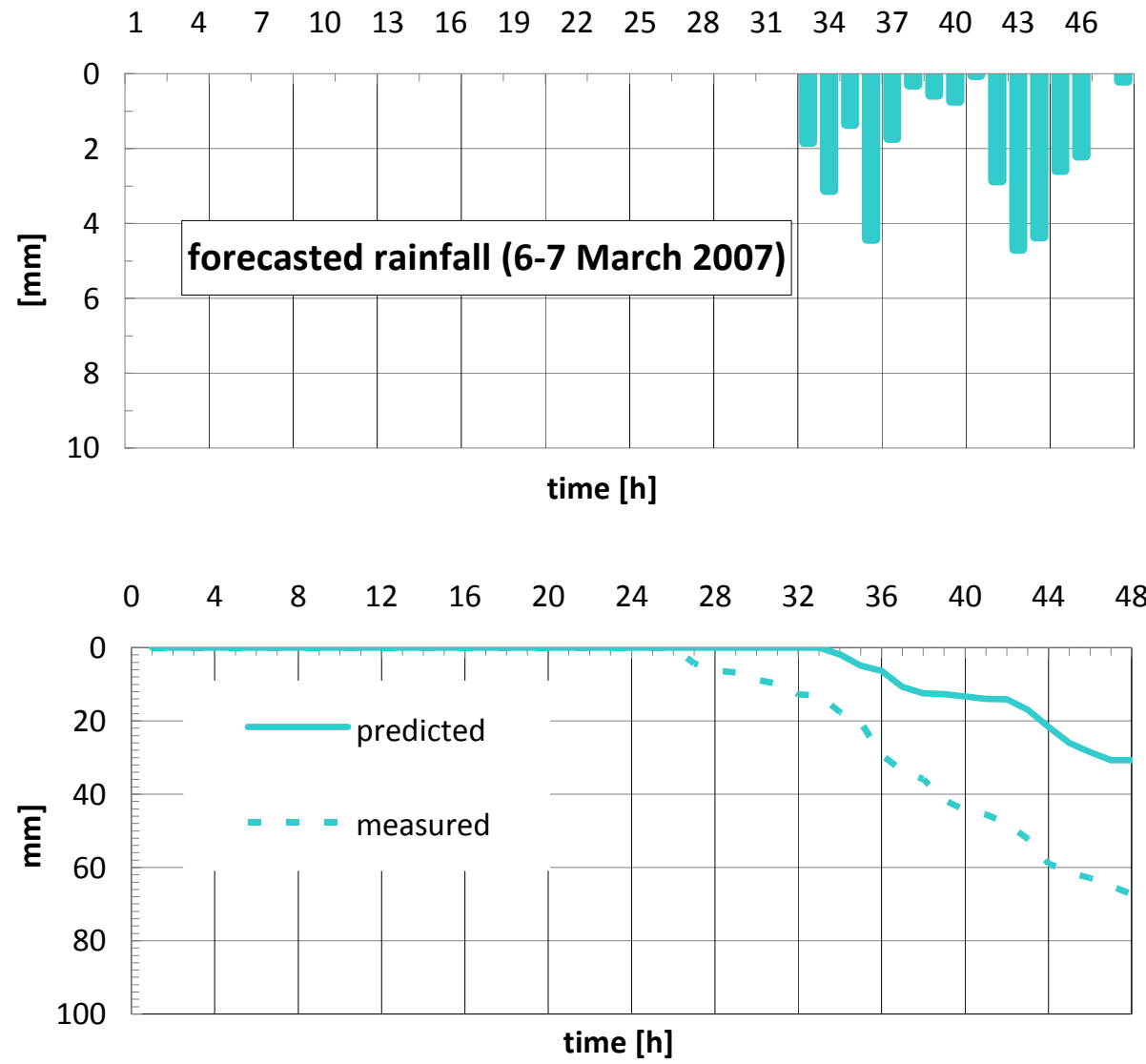

Fig. (9). Second test case: hourly rainfall height and cumulative rainfall height during 6-7 March 2007, evaluated at point A of Fig. (3) in the site of Cervinara. 

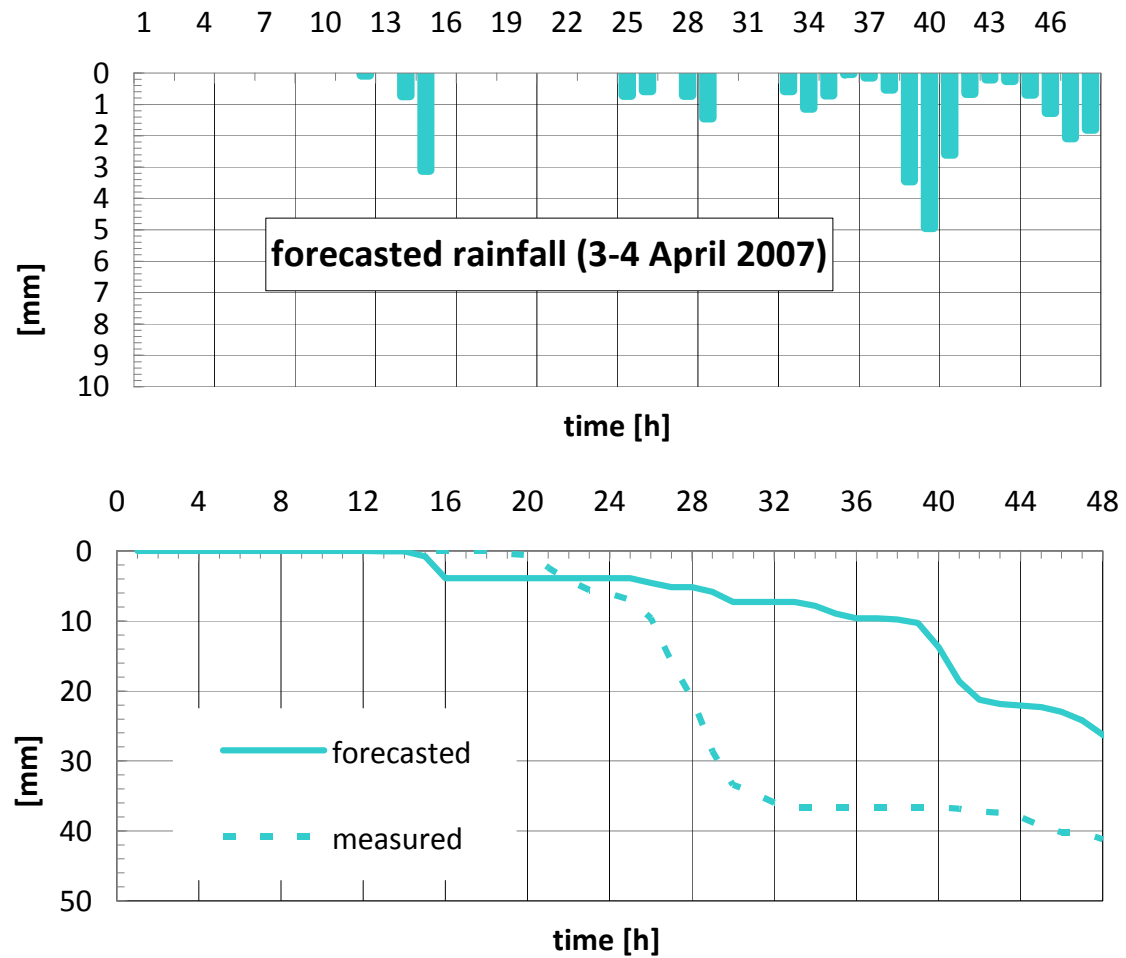

Fig. (10). Third test case: hourly rainfall height and cumulative rainfall height during 3-4 April 2007, evaluated at point A of Fig. (3) in the site of Cervinara.

\section{Cervinara test case : 3-4 April 2007}
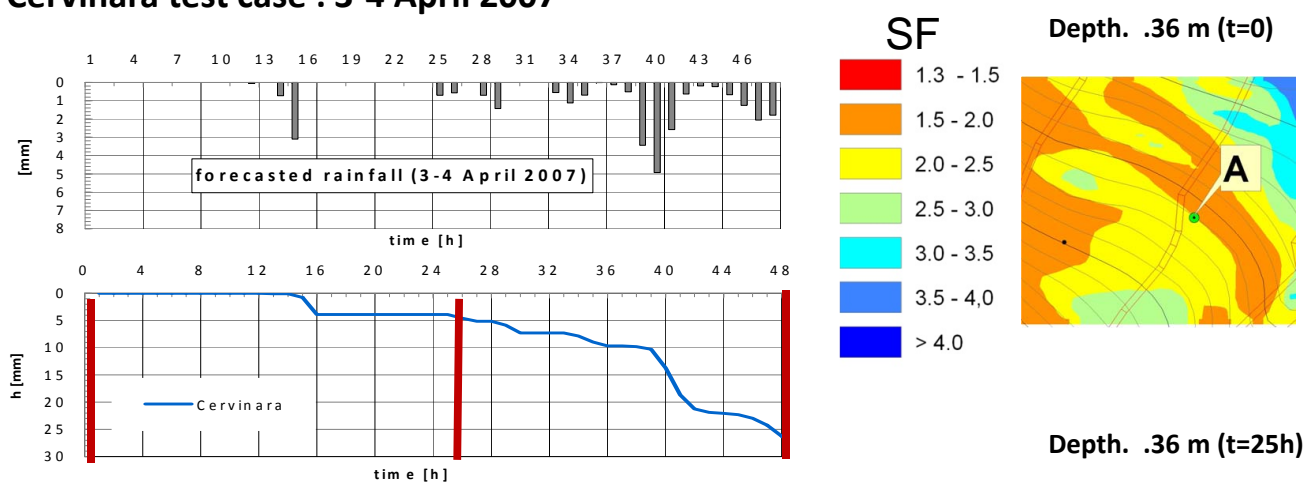

Depth. $1.92 \mathrm{~m}(\mathrm{t}=0)$

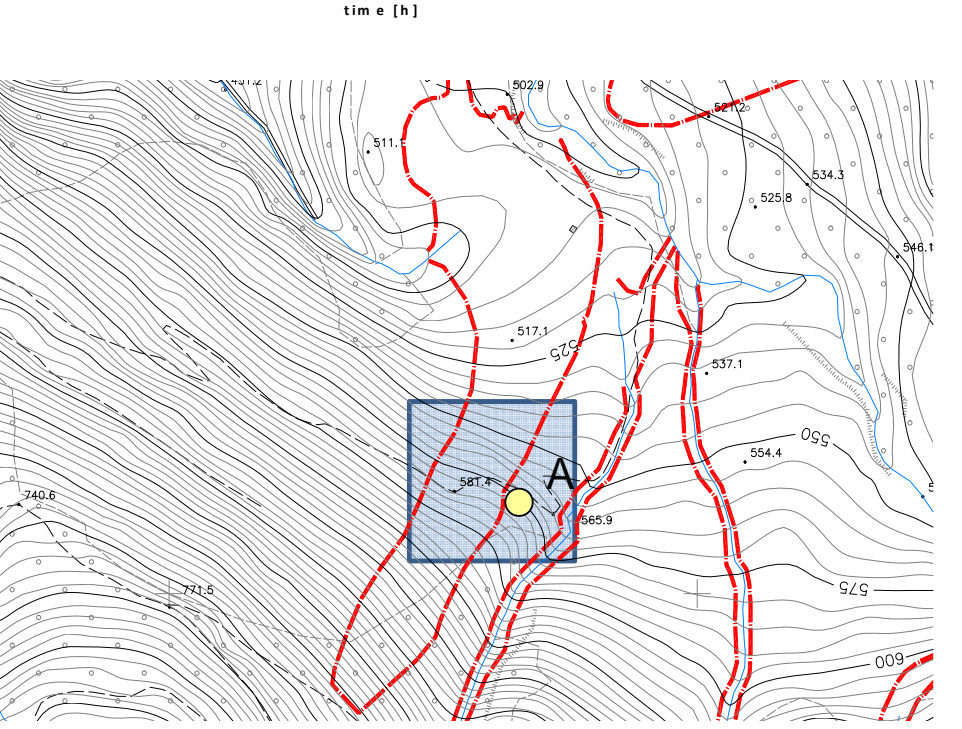

Depth. $.36 \mathrm{~m}(\mathrm{t}=25 \mathrm{~h})$
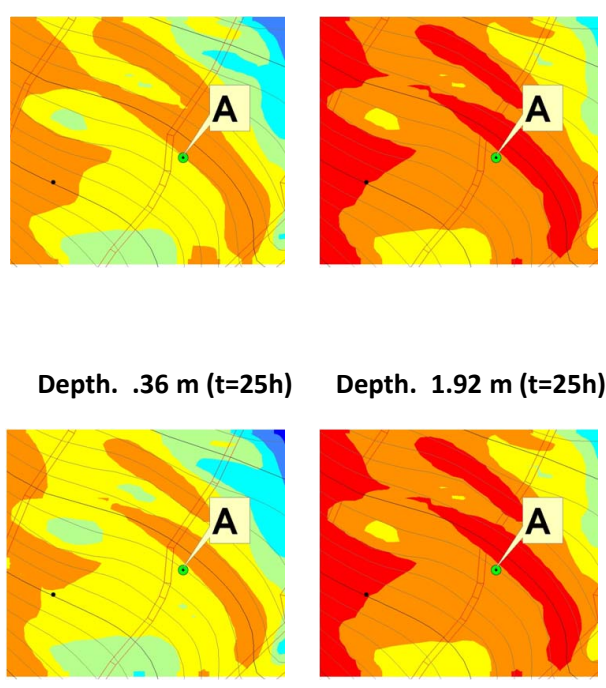

Depth. $.36 \mathrm{~m}(\mathrm{t}=48 \mathrm{~h})$
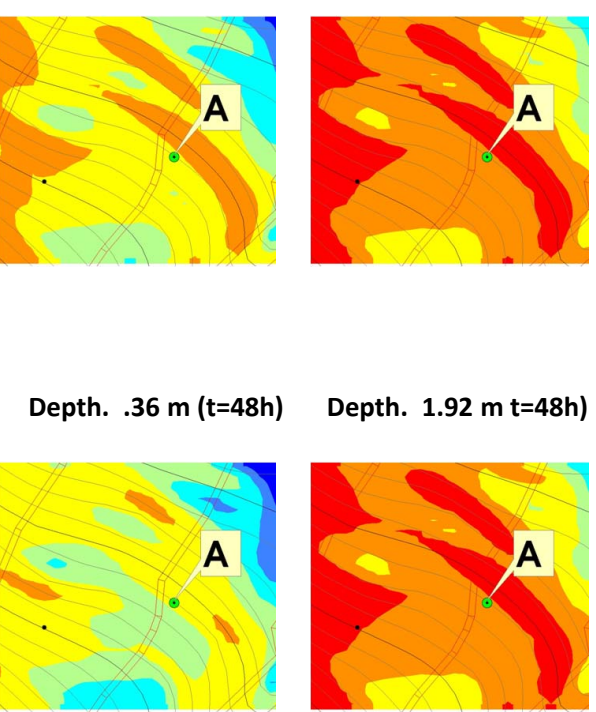

Depth. $1.92 \mathrm{~m} \mathrm{t}=48 \mathrm{~h})$

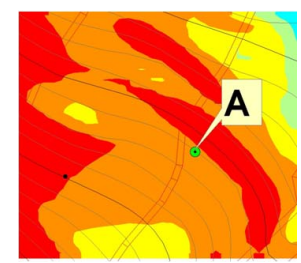

Fig. (11). First test case at Cervinara site: distribution of safety factors vs time at depths of $0.36 \mathrm{~m}$ in the selected area. 
Cervinara test case : 3-4 April 2007
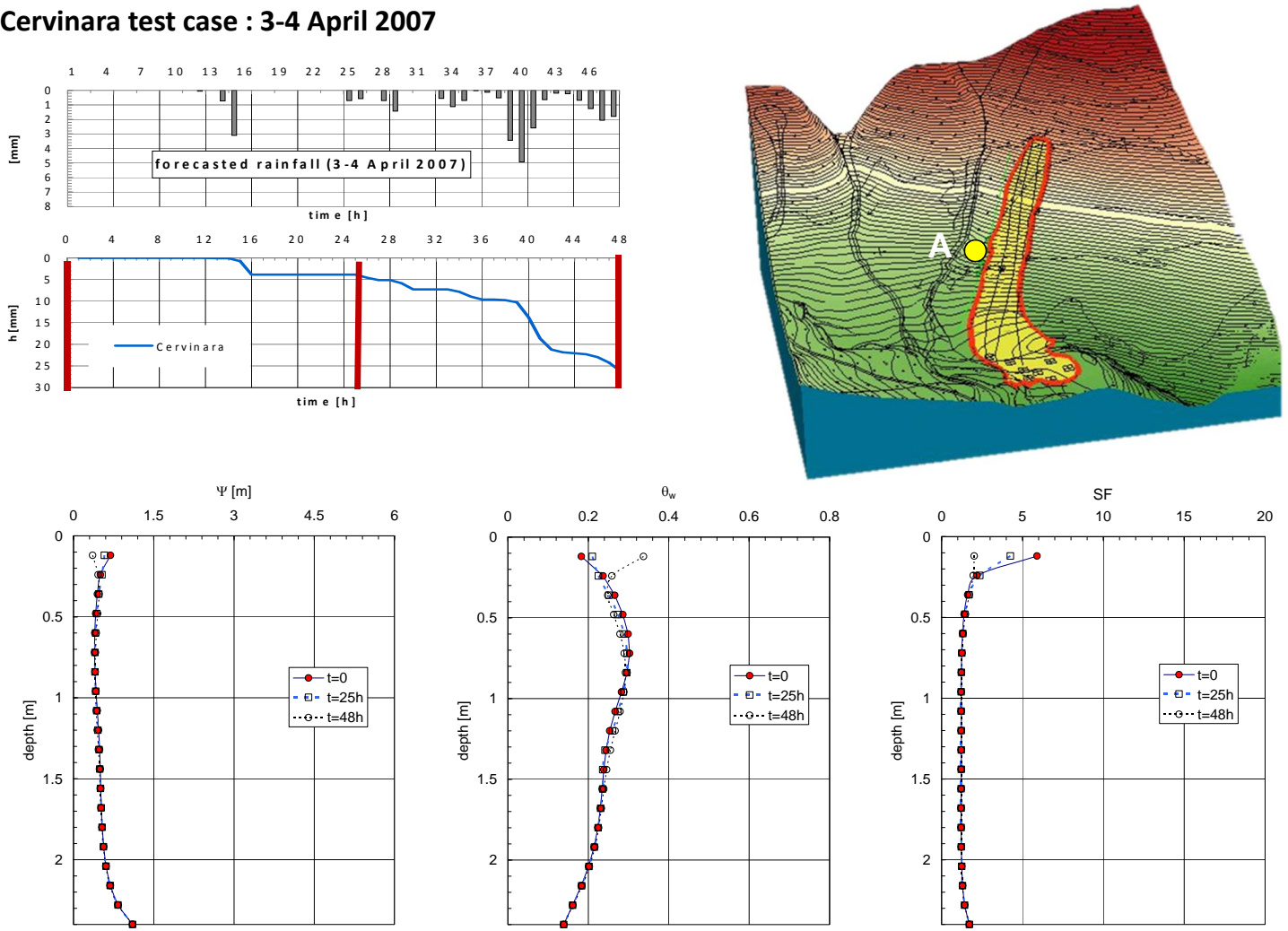

Fig. (12). First test case at Cervinara site: capillary height, volumetric water contents and safety factors profiles at point A.

\section{Cervinara test case : 6-7 March 2007}
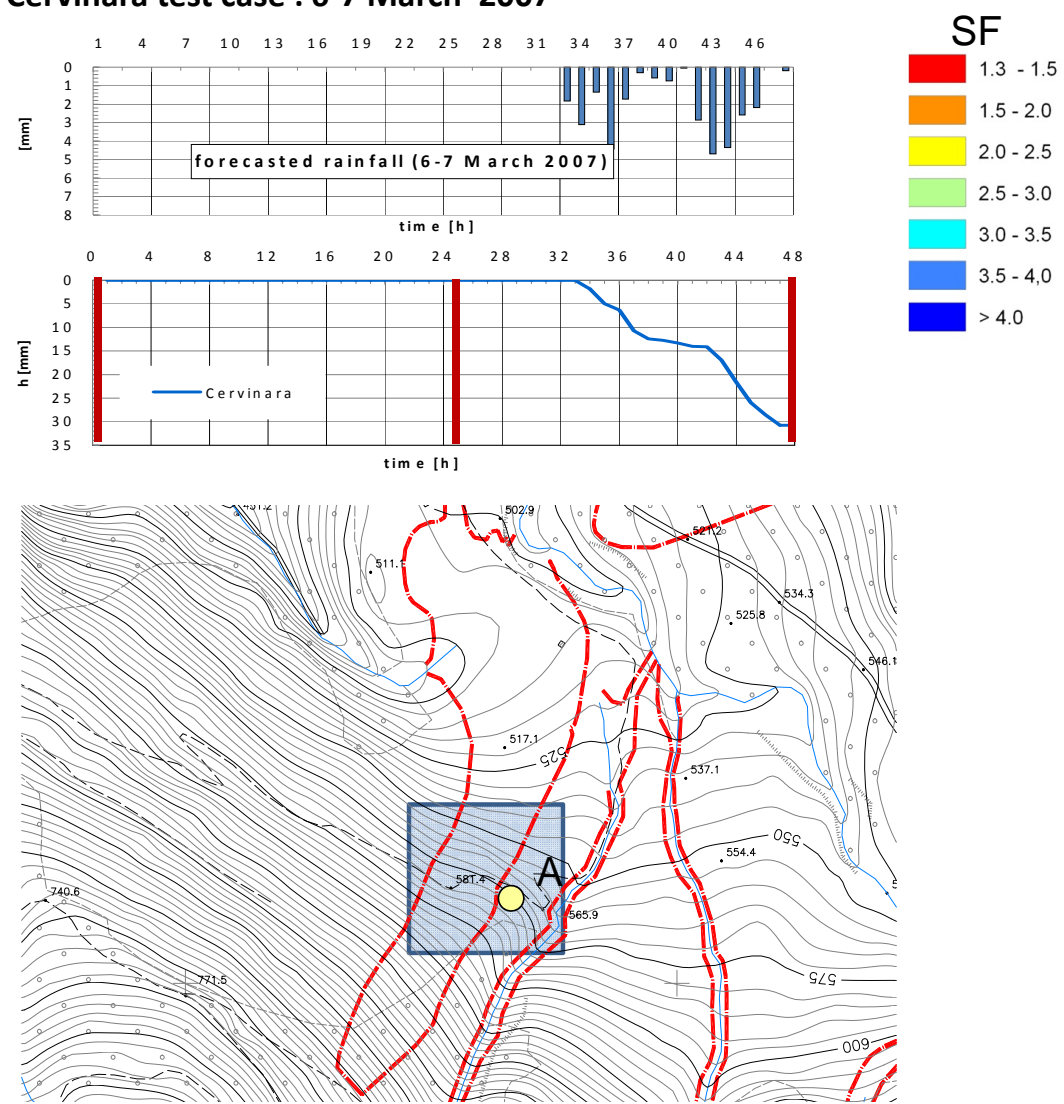

Depth. $.36 \mathrm{~m} \mathrm{(t=0)}$

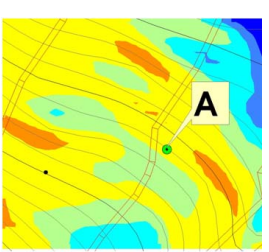

Depth. $.36 \mathrm{~m}(\mathrm{t}=\mathbf{2 5 h})$

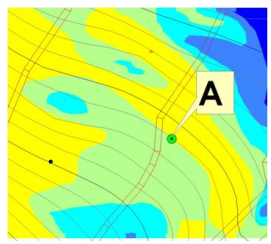

Depth. $.36 \mathrm{~m}(\mathrm{t}=48 \mathrm{~h})$

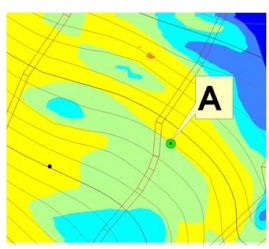

Fig. (13). Second test case at Cervinara site: distribution of safety factors vs time at depths of $0.36 \mathrm{~m}$ in the selected area. 


\section{Cervinara test case : 6-7 March 2007}
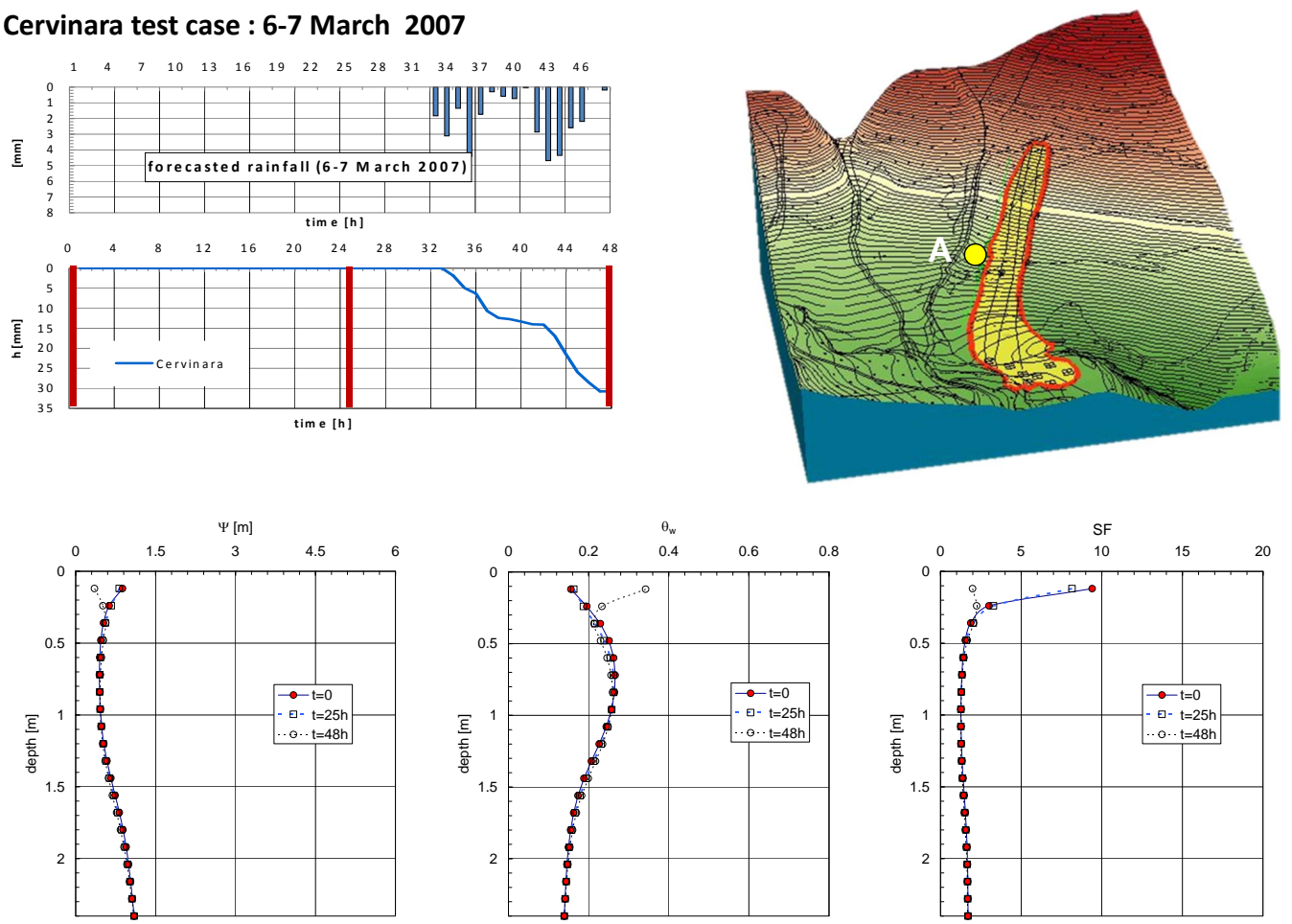

Fig. (14). Second test case at Cervinara site: capillary height, volumetric water contents and safetyfactors profiles at point A.

\section{Cervinara test case : 6-10 February 2007}
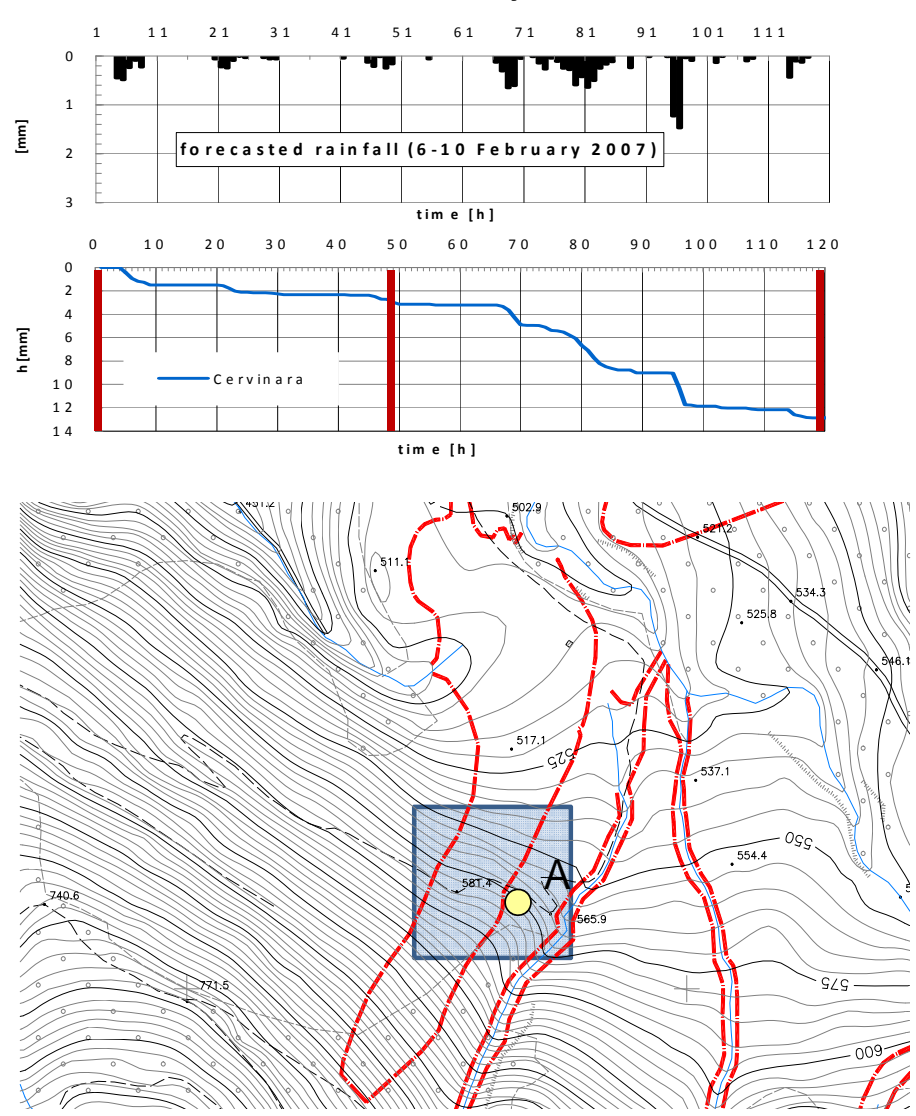

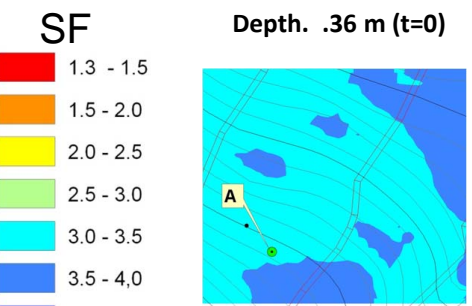

Depth. $.36 \mathrm{~m}(\mathrm{t}=49 \mathrm{~h})$

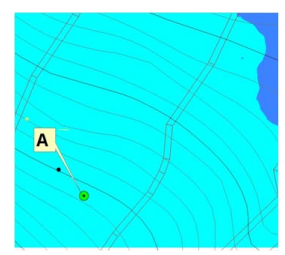

Depth. $.36 \mathrm{~m}(\mathrm{t}=120 \mathrm{~h})$

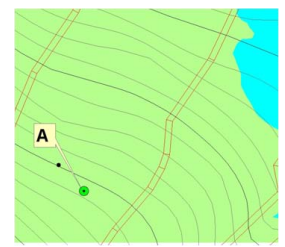

Fig. (15). Third test case at Cervinara site: distribution of safety factors vs time at depths of $0.36 \mathrm{~m}$ and $1.92 \mathrm{~m}$ in the selected area. 
Cervinara test case : 6-10 February 2007
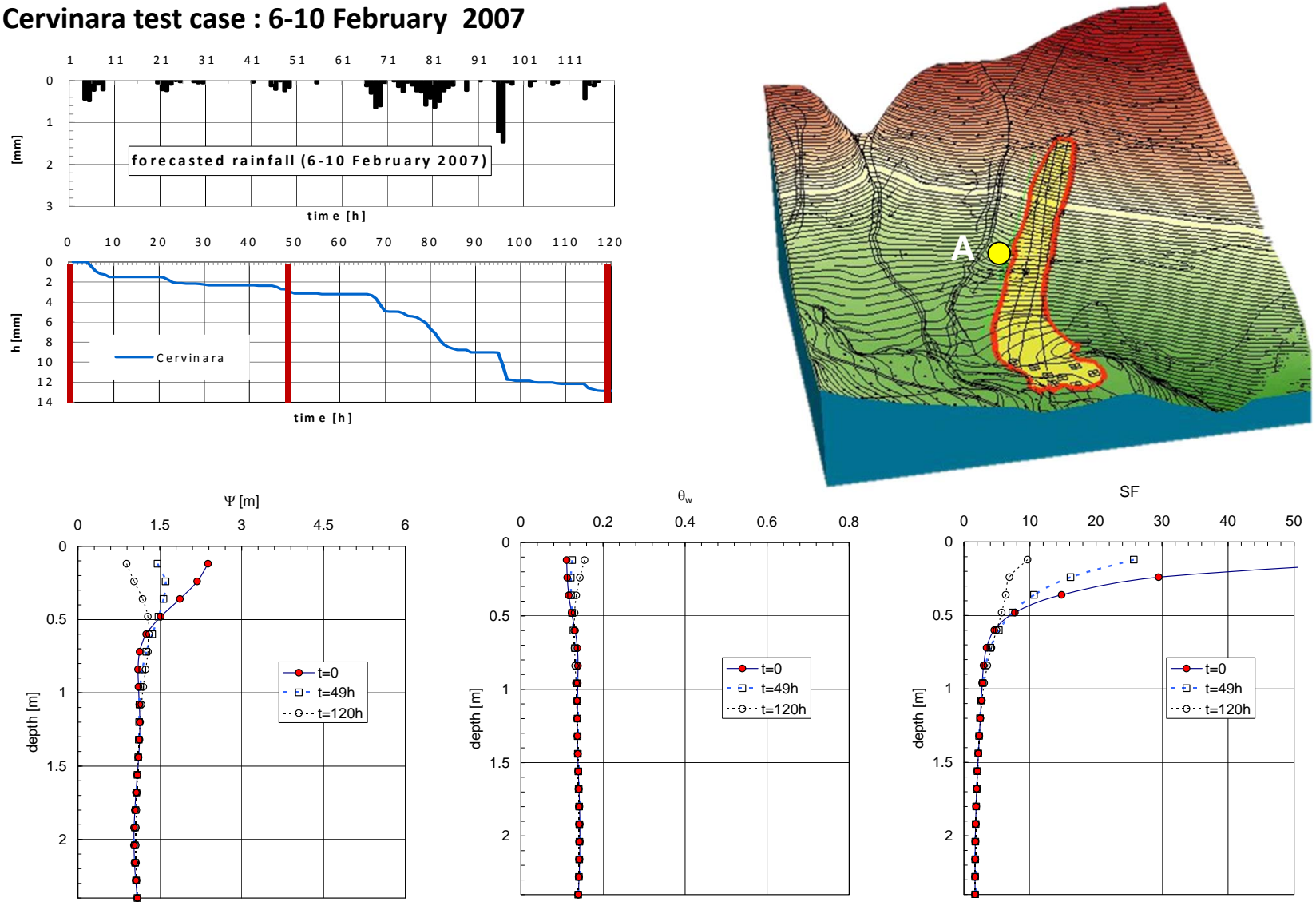

Fig. (16). Third test case at Cervinara site: capillary height, volumetric water contents and safety factors profiles at point A.

Comparing the three tests it can be observed that:

1. as expected, the wetting front depth is influenced by the duration of the event: in the first case (DT=120 hours) there is a strong reduction in capillary height up to $60-80 \mathrm{~cm}$ (while in the second case (DT $=12$ hours) the maximum depth reached by the infiltration process is about $36 \mathrm{~cm}$. This clearly influences the depth at which the safety factor reduction is non-negligible.

2. the final value of the safety factor is lower for test case 3 where rainfall had a greater cumulative height, and starting from initial condition with higher volumetric water content (lower capillary height).

In all three tests, the proposed MDSS successfully provided quantitative information about the link between forecasted rainfall and slope response, as it considered the spatial and temporal distribution of forecasted rainfall, the physical properties of soils (in saturated and unsaturated conditions) and the initial conditions (provided by the numerical simulation initialized from monitoring).

In Fig. (10), the pink points represent the final conditions simulated for the three test cases. In the test cases 1 and 2, the final points fall within the green zone: even in case of further infiltration until slope failure, the occurrence of flowslides can be excluded. Also in the third case, the occurrence of flowslide is very unlikely: the final point falls within the yellow zone, but the degree of saturation (about 40\%) is so far from saturation that eventual failure would anyway occur with the soil in unsaturated conditions.

\section{CONCLUSIONS}

The paper presents a Multidisciplinary Decision Support System (MDSS) for the analysis of the link between forecasted rainfall and its effects in terms of infiltration, slope stability and vulnerability on steep slopes covered with pyroclastic deposits. The system proposes an approach to provide quantitative information about the evolution, corresponding to forecasted rainfall, of hydrological and geotechnical variables such as water content, degree of saturation and suction, that are of fundamental importance to detect cases in which rainfall-induced slope failures may evolve into flowslides. In fact, such information is of extreme importance for the authorities in charge of land management in the southern Apennines, to avoid from activating prevention measures in the cases of landslides that will not evolve into catastrophic flowslides, thus allowing the reduction of the 'false alarms'(Damiano and Olivares 2010).

Moreover, by using historical time series of rainfall events, currently available thanks to the highly spread pluviometric monitoring systems, the hydrological-geotechnical model can provide warning maps for different risk scenarios, which may support the authorities in charge of land planning and management in their decision processes.

\section{CONFLICT OF INTEREST}

The authors confirm that this article content has no conflicts of interest. 


\section{ACKNOWLEDGEMENT}

The authors thank the COSMO consortium, the SMAUSAM (General Office for Air Space and Meteorology of the Italian meteorological service), for the availability of the COSMO LM model for research application and for the Provision of Guidance and Support. The research work was funded by the Department of Economics of the University of Naples "Federico II", the Department of Civil Engineering of the Second University of Naples and the Euro-Mediterranean Centre for Climate Change of Capua.

\section{REFERENCES}

[1] Castro G. Liquefaction of sand. Ph.D. Thesis, Division of Engineering and Applied Physics, Harvard University: Cambridge, Mass 1969.

[2] Casagrande A. Liquefaction and cyclic deformations of sands-A critical review." Proceeding of the $5^{\text {th }}$ Punornericm Conference on soil Mechanics and Foundation Engineering, Buenos Aires. Harvard Soil Mechanics Series, 88: Cambridge, Mass 1976

[3] Yamamuro JA, Lade, PV. Static liquefaction of very loose sands. Can Geotech J 1997; 34: 905-17.

[4] Been K, Jefferies MG. A state parameter for sands. Geotechnique 1985; 35: 115-28.

[5] Sladen JA, D'Hollander RD, Krahn J. The liquefaction of sand, a collapse surface approach. Can Geotech J 1985; 22: 564-78.

[6] Olivares L. Static liquefaction: an hypothesis for explaining transition from slide to flow in pyroclastic soils. Proceedings of ISSMGE TCT-11. Transition from Slide to Flow: Mechanisms and Remedial Measures; Trabzon, TC-11 and ATC-9; Kyoto, Japan 2001. vol. 1: pp. 1-14

[7] Wang G, Sassa K. Factors affecting rainfall-induced landslides. Geotechnique 2001; 51: 587-99.

[8] Olivares L, Picarelli L. Susceptibility of loose pyroclastic soils to static liquefaction: some preliminary data. Proceedings of International Conference on Landslides - Causes, Impacts and Countermeasures, Davos 2001; vol. 1:pp. 75-85.

[9] Chu J, Leroueil S, Leong WK. Unstable behaviour of sand and its implications for slope instability. Can Geotech J 2003; 40: 873-85.

[10] Olivares L, Picarelli L. Shallow flowslides triggered by intense rainfalls on natural slopes covered by loose unsaturated pyroclastic soils. Géotechnique 2003; 53: 283-8.

[11] Leroueil S. Geotechnics of slopes before failure. Proceedings of IX International Symposium on Landslides: Evaluation and Stabilization, Rio de Janeiro,Balkema: Rotterdam 2004; pp. 863-84.

[12] Olivares L, Damiano E. Post-failure mechanics of landslides: laboratory investigation of flowslides in pyroclastic soils. J Geotech Geoenviron Eng ASCE 2007; 133(1): 51-62.
[13] Damiano E, Olivares L. The role of infiltration processes in steep slopes stability of pyroclastic granular soils: laboratory and numerical investigation. Nat Hazards 2010; 52 (2): 329-50.

[14] Hallegate S, Dumas P, Hourcade J-C. A Note on the Economic Cost of Climate Change and the Rationale to Limit it Below $2{ }^{\circ} \mathrm{C}$. The World Bank Policy Research Working Paper 5179, 2010: pp. $1-17$.

[15] Klibanoff P, Marinacci M, Mukerji S. A smooth model of decision making under ambiguity. Econometrica 2005; 73(6): 1849-92.

[16] Doms G, Schattler U. The non-hydrostatic limited area model LM (Lokal Model) of DWD. Part I. Scientific documentation. Deutscher Wetterdienst, 1998. [Available online at http://cosmomodel.cscs.ch.]

[17] Simmons AJ, Burridge DM, Jarraud M, Girard C, Wergen W. The ECMWF medium-range prediction models: development of the numerical formulations and the impact of increased resolution. Meteorol Atmos Phys 1989; 40: 28-60.

[19] DamianoE, Mercogliano P, Netti N, Olivares L. A "Simulation Chain" to define a Multidisciplinary Decision Support system for Landslide risk management in pyroclastic soils. Nat Hazards Earth Syst Sci 2012; 12: 989-1008

[20] Damiano E, Olivares L, Picarelli L. Steep-slope monitoring in unsaturated pyroclastic soils. Eng Geol 2012; 137-138: 1-12.

[21] Greco R, Guida A, Damiano E, Olivares L. Soil water content and suction monitoring in model slopes for shallow flowslides early warning applications. Phys Chem Earth 2010; 35: 127-36.

[22] van Genuchten MTh. A closed-form equation for predicting the hydraulic conductivity of unsaturated soil. Soil Sci Soc Am J 1980; 44: 615-28.

[23] Brooks RH, Corey AT. Hydraulic properties of porous media. Hydrology Paper N.3, Colorado State University: Fort Collins, Colorado 1964.

[24] Fredlund DG, Rahardjo H. Soil Mechanics for Unsaturated Soils. In Wiley-Interscience Publication. New York: John Wiley \& Sons 1993.

[25] Jury WA, Gardner WR, Gardner WH. Soil physics. New York: Wiley 1991.

[26] Netti N, Olivares L, Mercogliano P. Landslide risk management: a multidisciplinary approach to define a decision support system for rainfall induced landslides. G.R.A Open Access Pub Earth. Planet Space Sci 2011: 13: EGU2011-7789-1

[27] Netti N. Natural Hazards, Poverty Traps versus Economic Growth. G.R.A Open Access Pub Earth Planet Space Sci 2012; 14: EGU2012-6335-1

[28] Greco R, Guida A. Field measurements of topsoil moisture profiles by vertical TDR probes. J Hydrol 2008; 348: 442-51.

[29] Olivares L, Damiano E, Greco R, et al. An instrumented flume for investigation of the mechanics of rainfall-induced landslides in unsaturated granular soils. Geotech Test J 2009; 32(2): 1-11.

[30] Picarelli L, Olivares L, Avolio B. Zoning for flowslide and debris flow in pyroclastic soils of Campania Region based on "infinite slope" analysis. Eng Geol 2008; 102(3-4): 132-41.

Received: May 03, 2012

Revised: July 09, 2012

Accepted: September 07, 2012

(C) Netti et al.; Licensee Bentham Open.

This is an open access article licensed under the terms of the Creative Commons Attribution Non-Commercial License (http://creativecommons.org/licenses/by-nc/3.0/) which permits unrestricted, non-commercial use, distribution and reproduction in any medium, provided the work is properly cited. 